\title{
Título, paratexto, texto y contexto en la poesía española de los 80: Felipe Benítez Reyes
}

\author{
Rafael Morales BARBA \\ Universidad Autónoma de Madrid
}

\begin{abstract}
Encontrar alguna preceptiva sólida que establezca vinculaciones fiables entre título y texto es prácticamente imposible, salvo desde una pragmática y contextos internos en el autor y una época. Paratextos, prólogos, trayectorias y lecturas, afinidades, generan a su vez pistas de interpretación, más que certezas. En los años 80 existen demasiadas poéticas como para establecer vinculaciones comunes desde esta perspectiva salvo entre grupos afines. Esa vinculación, pese a las contigüidades se diluye en ocasiones con temas como la luna, intergeneracionales, tal y como hacemos al mirar sucintamente la obra de Alberti y Benítez desde la coincidencia de asuntos.
\end{abstract}

Keywords: Poesía, 1980, luna, elegía, tiempo, lírica, Felipe Benítez Reyes

La relación entre el título y la obra literaria, entre el libro de poemas o el poema como obra unitaria y su título, se presenta hoy como un interrogante. $\mathrm{O}$ como un nudo complejo que no puede estandarizarse por su amplitud y dificultad. Los parámetros de análisis propuestos actualmente no saben, ni pueden abarcar el extravío lírico, donde la fórmula puede llegar a ser más importante que la inventio. En cualquier caso no tengo páginas para abordar la cartografía teórica del problema desde la lírica, ni desde la historiografía, salvo este breve apunte al respecto. No voy a repetir para situar al lector esa diacronía recientemente repasada por Max Roi en su recorrido desde el origen, la cinta identificadora del volumen, hasta los planteamientos sobre aquella simple cinta en que se han convertido los prólogos y títulos. Asunto que ya Borges por 1974 presentó al público, y Umberto Eco, Hoeck, Genette detallan. Teóricos mucho más aplicados a la narratología que al poema lírico, donde el género trae por la propia identidad del poema como mero artificio verbal en muchas poéticas contemporáneas, una serie de problemas que rompen con facilidad las identidades entre título y obra. A cualquiera que se le plantee las relaciones entre poema y título le surgirán pronto algunas inequívocas sobre los límites en poesía, pues la épica clásica, desde La Ilíada hasta La Araucana o el Canto General, donde prima el asunto, como en la novela. Por tanto, hablar desde la lírica, y más concretamente de la de los siglos xx y xXI, necesita su espacio hermenéutico propio. Diferenciado no solo de los otros géneros, sino de las distintas modalidades de poesía, para centrarse en la lírica. Quizá la misma brevedad del género lírico y la falta de obligación de titular un poema, pero sí los libros, generen una personalidad 
diferenciada a la hora de acercarnos al texto. En principio, vincular título y poema, por su brevedad, siempre será de una forma más abarcadora que la polisemia de la novela con su título. En el fondo, ¿qué dice Climas de André Maurois o La peste de Camus, más explícita, Los hermanos Karamazov, sobre la honda realidad de las novelas que se acogen o amparan tras esos nombres? En cualquier caso un título es una clave interpretativa lacónica, no siempre abierta o capaz, parcial habitualmente, si bien mantiene Umberto Eco que El rojo y negro la esconda, tras el color de la milicia o de la iglesia, pues eso solo pone al frente los dos poderes que se debatían, pero nada más. Ni tan siquiera $A$ la búsqueda del tiempo perdido cuenta algo del título, salvo que se refiera a la palabra Memorias, lo cual tampoco explica nada de qué tipo de memorias, desde qué perspectiva, clase, identidad, etc., se refieren en su intencionalidad o asunto. El título se reduce a simple pista, poco más que la cinta que enrollaba el volumen, y su importancia en el fondo radica en la captatio y en esa pequeña orientación. Es una pista que apenas dice algo incluso en los libros de poesía unitarios, pues mantener que Diario cómplice es relevante desde la información no lo es sino desde la pragmática o contexto de la lírica de García Montero en su tradición de poeta de amor. Pero el título realmente poco dice, salvo su propia gracia nominativa, que apunta a la unión de una joven pareja tanto como a su desunión en Habitaciones separadas. Desde ese pragmática interna sí podemos averiguar algunas cosas, pero solo si olvidamos que en poesía la fórmula puede ser el asunto (cosa que nunca entendió María Zambrano). Si la narración es siempre en algún grado insuficiente u opaca por su propia plurisemasia o polifonía de significados, en la lírica la opacidad puede ser mucho más absoluta o deíctica simplemente desde ese absolutismo que en el fondo poco dice de lo importante del poema, es decir, de su fórmula y modos, vericuetos expresivos y alambicamientos conceptuales. Sin duda el paratexto, el prólogo o las palabras de presentación de los libros de poesía, pueden ser muy significativos, pues a veces son meros ejercicios de seducción y ocultación, casi justificación de lo injustificable en algunos casos (pero eso es otra historia). A poco que el crítico se interrogue encontrará que la vinculación del título al sentido nada aclara en ocasiones, o en ciertas corrientes estéticas. Piénsese en el «Soneto en IX» o en poemas ultraístas. Piénsese en poemas concretistas, en Michaux, Brodsky, o en Robert Lowell y la relación entre título y poema. ¿Cuál es la relación entre La joven parca y su título? Un libro de poemas puede ser unitario y establecer mayor o menor vinculación con la obra como ocurre con el Romancero Gitano, Poemas del toro, etc. Quizá un análisis de los paratextos, vía grabaciones de presentaciones de sus libros por parte de los poetas, sea el objetivo de esta moderna teoría del título, dado que los libros de poemas no suelen llevar prólogo, salvo antologías, obras completas o ediciones críticas. 
El poema unívoco, puede ser obra en sí misma, no precisa pistas obligadamente, como demuestran las titulaciones en blanco y numéricas. Lo ya expresado acerca de Maxi Rey en su impresionante trabajo filmando al poeta en diferentes actos. Ciertamente en un poema breve, un soneto o en una soleá, la vinculación puede ser mayor, por la unidad teleológica del sentido. Ya hemos comentado que la expresión en poesía puede ser el sentido en ciertos poemas herméticos o simplemente lúdicos de corte vanguardista o neovanguardista, o los experimentales. ¿Qué sentido tendría dar pistas sobre la falta de sentido de muchos poemas (si lo fueran, pero eso es otra cuestión), salvo titularlos todos «SINSENTIDO I, 2, 34 »? ¿O habrá que esquivar este asunto desde el título cuando el fervor del lenguaje se convierte en asunto? Pensemos también en Lezama Lima, salvo Fragmentos a su imán y próximos (aun así). La vinculación parece venir favorecida por la permeabilidad del texto y por la ausencia de una polifonía de significados, es decir, por la brevedad que constriñe un haz de significaciones. Sin duda la titulogía, por decirlo con Claude Duchet, necesita un esfuerzo específico que tal vez no merezca la pena para establecer cualquier tipo de principio sistematicidad y comprensión del texto lírico desde el título, salvo desde una pragmática interna, atenta al propio idiolecto lírico del autor. O, si se prefiere, a la red de correspondencias internas creadas por el autor contextualmente en su propia trayectoria. Una lectura contextual, pragmática, desde esa perspectiva parece que sea imprescindible para poder interpretar esa vinculación, cuando acontece en un período de tiempo próximo dentro de una tendencia, tal y como puede ocurrir entre poetas de las poéticas del silencio, de la experiencia, del realismo, la nueva sentimentalidad, etc. Es decir, de una mirada contextual donde época o generación, corriente y trayectoria del autor se conjugan para generar una pista de la intencionalidad o vinculación entre título y libro.

Es posible, por tanto, con esta perspectiva, un estudio diferenciado desde lo remático y lo temático, asuntos y tipos en un pequeño recorrido diacrónico. Nosotros lo haremos intergeneracionalmente con un asunto: la luna como motivo en Rafael Alberti y Felipe Benítez Reyes. Además de esa pequeña interrelación temática entre título y obra en dos escritores gaditanos a lo largo del tiempo, daremos algunas pinceladas sobre la relación entre obra y título en la poesía española entre I980 y 2000. Unos pocos nombres a los que apenas podemos dar espacio y sin que podamos ser mínimamente exhaustivos, teniendo en cuenta que en España se publican más de 3.500 libros de poesía al año desde hace más de veinte, según las fuentes de la Dirección General del Libro. Hablaremos, pues, de un selecto grupo de nombres como el citado Felipe Benítez Reyes, Julio Martínez Mesanza, Luisa Castro, Blanca Andreu o Carlos Marzal. Si atendemos al primero de ellos, Benítez Reyes (I960), un poeta fundamentalmente elegíaco y melancólico, y 
seguramente uno de los verbos más delineados y pulcros en el fin de siglo español desde su virtuosismo plástico, sacaremos la conclusión de que el nombre de sus libros mantiene siempre una relación ambigua, en apariencia, con el asunto principal, pero no contextualmente. El paso del tiempo y la melancolía por lo ido, pueden identificarse desde un neobarroquismo y desde la misma ascendencia o potestad interna de unos títulos sobre otros en función de la poética del autor, que elimina la interpretación abierta u horizonte posible, para constreñir el sentido en una dirección. En efecto, ya en Paraíso manuscrito está presente el tema del tiempo y la elegía, si bien el título apenas dice nada. En los Vanos mundos (1985), el título podía interpretarse desde una mirada abierta como la superficialidad de la vida acelerada de un joven burgués entre fiestas y primeros problemas, incluso sin leer el título podría interpretarse políticamente como un ataque al consumismo burgués, si no fuera porque es como un desdén esteticista por ciertos mundos juveniles propios, que en el fondo apuntan más al vano mundo desde los vanos o superficiales de la juventud o, si se prefiere, el comienzo de una mirada neobarroca atada hiperestésicamente al transcurso del tiempo desde una intimidad doliente y elegíaca. Si bien en Sombras particulares (I992), se sugiere un espacio secreto y nublado del yo donde se conjuran inquietudes irresueltas y demonios interiores, sin olvidar, por supuesto, la herida del tiempo. Escaparate de venenos (2000) hay que asumirlo contextualmente desde el título en conjunción con Los vanos mundos, es decir, solo es posible interpretarlo desde esa pista inicial de otro título de Benítez Reyes. Este escaparate no señala una vitrina donde se acumulan frascos ponzoñosos a la manera en que El libro de los venenos (2006) de Antonio Gamoneda hace una lectura del Discórides en su libro VI hablando de pócimas. El título del poemario de Benítez sin las pistas de los anteriores poco diría en la polisemia abierta que ahora se dirige igualmente a los demonios personales marcados por los escritos previos, es decir, al vacío y la melancolía de los espacios huecos transitados de tiempo y memoria, desde la suntuosidad alambicada del esteticismo firme, sin holguras, engarzado como una joya de Lalique en su obsesión. De la misma manera que El contemplado (1946) de Pedro Salinas supone una ruptura desde la implicación semántica impensable con el asunto desde su trayectoria, más proclive a titularlo La contemplada, al menos, hasta saber que se trata del mar y no de la mar, o de ella. En este sentido el escaparate de Felipe Benítez Reyes es ese ya visto, con su veneno: el tiempo, y, desde ahí, El equipaje abierto señala el fin del viaje, cuando todo está explícito con motivo de una maleta encontrada en la playa. La falta de secretos en un pequeño espacio abierto con lo íntimo y su hueco a la manera del cangrejo de Juan Ramón en Espacio (el yo abierto y sin nada que ocultar ya de la maleta privada), e incluso el desnudo de equipaje machadiano de los hijos de 
la mar, del tiempo, en ese desvelamiento del fin de la magia y el encuentro fenomenológico con la realidad desnuda, abierta, según hemos adelantado.

Todo ello nos lleva a leer los títulos de Felipe Benítez desde esa trayectoria interna de la falta de entusiasmo, del fin del vitalismo y de la ausencia de voluntad en el texto para remitirse a lo monotemático en una especie de patología obsesiva. Lectura de un título desde la trayectoria propia, pero sin olvidar el contexto, o la contextualidad de un momento en sus diferencias y afinidades con los próximos desde algún aspecto y algún momento, también en lo generacional, desde la perspectiva de Juan Lamillar, José Mateos, Luis García Montero o Carlos Marzal, entre otros. Tomado el asunto desde esta perspectiva generacional y atendiendo a Luis García Montero (I958), poeta no sujeto a la inventio casi monotemáticamente como Benítez Reyes, asistiremos a otra perspectiva interna donde cualquier intento de regularizar el asunto con el título cae tanto desde la perspectiva del autor como generacionalmente. El tema de la melancolía, sin embargo, parecería venir indicado por un libro inicial, escrito junto a Álvaro Salvador, con un título marcado por la historia de la literatura. Nos referimos a Tristia (1982), aunque poco tenga que ver con las circunstancias, asunto y tono del libro de Ovidio. No lo es ni en la coyuntura de los poemas del poeta latino, ni en el contenido del libro, pues es de amor sin anhelos de la tierra perdida, de juventud y gozoso, como no podría ser menos. Si lo hiciera sería a través de una extraña sinécdoque al tomar a Ovidio como poeta amoroso desde otros libros, pero paradójicamente no en este que habla desde el exilio y sus dolores por causa de una vida escandalosa. Tristia no indica nada en sentido estricto respecto al libro, es solo un guiño culto y seductor de quien no ha pasado por esos mundos ni habla por tanto desde ellos, sino un libro de tristes desde la primera juventud o el primer bucle melancólico. Algo dijo el bueno de Jon Juaristi con otra perspectiva contra el nacionalismo basado en mitos falsos. Tal vez se quisiera hacer un homenaje al exilio interior frente al exterior, a los vencidos exiliados en el suelo propio, pero eso no ocurrirá hasta el libro siguiente, El jardín extranjero de I983, y en poemas como «Para ponernos nombre (I94I)». Es decir, desde un homenaje al caído, al vencido capaz de hacer crecer su amor en un ambiente hostil, exiliado en su patria, exiliado en un sentido figurado y, sin embargo, real. Con lo cual, la tesis del título como mera sugerencia frente al sentido tiene un peso real. Afinar tan estrictamente nos llevaría hasta el Umberto Eco de la sobreinterpretación y sin él, igualmente. En el fondo Tristia responde desde el nombre a la elección de un nombre sugerente para encubrir una poesía amorosa, sin exilio. Diario cómplice (1987), era mucho más explícito en esa conjunción de intimidad y poema, de aventura inicial. Ya Las flores del frío (I990), sin embargo, anticiparon el desamor de Habitaciones separadas (I994). Hubo una correspondencia de sentido muy explícita que rompía con la tradición inicial desde la 
titulogía al hilo de la propia vida o experiencia desde el amor al desamor y otra vez al enamoramiento de Completamente Viernes (1998). Poemario que desde el título no dice absolutamente nada, hasta que averiguamos al nuevamente enamorado y a su amor, Viernes. El caso del Carlos Marzal de El último de la fiesta (1987) o La vida de frontera (199I), donde se avisa de una vida al límite desde cierta perspectiva nocturna y bohemia, formando un duetto, de la misma manera que el descenso ad inferos conjuga otro en Los países nocturnos (1996) y Metales pesados (200I), donde el pesimismo de ser toca fondo explícito. Incluso desde el título en correspondencia con Benítez Reyes en el libro de 1996: frente a Sombras particulares, Metales pesados incrementaba el sentido desde esa perspectiva hablada de los venenos con Antonio Gamoneda y Felipe Benítez Reyes, pues ya se sabe que frente a pesados se prefiere hoy tóxicos, es decir, metales tóxicos o venenosos, lo cual conlleva una serie de contigüidades semánticas. Dejémoslo ahí, porque es difícil avanzar desde el modelo. ¿Pero qué nos dice, en el fondo, De una niña de provincias que se vino a vivir en un Chagall? Sin tema, según confesó la autora el 28 de marzo de I98I a Juana Salabert en El País. Poco indica el título salvo un libro donde el asunto es lo de menos frente a la explosión verbal como asunto. Báculo de papel apenas guarda relación con la mística del galardón que en teoría premia un libro místico y Capitán Elphistone (1988) sortea los hechos que dieron fama a George Elphistone, almirante inglés en las guerras napoleónicas. Claro está, si ese Elphistone fuera el referente histórico, pues la coincidencia no implica certeza. No la puede haber, sino sugerencia (como en Tristia) en esta idealización muy personal del marino, desde un texto hermético y sucinto, poco épico, y alejado de los personajes de Exilio o Saint John Perse, y los sortea, pues el propósito es mucho más personal. Si nos fijáramos en otra poeta de referencia del momento, Luisa Castro Legazpi, podríamos decir tres cuartas partes de lo mismo, pues los sugerentes títulos son una mera sinécdoque del rico mundo interior de la poeta gallega, desde Los versos del eunuco (1987) o el sugerente Baleas e baleas (1988), que poco anticipan del poema, salvo que uno interprete que la poeta gallega es arponera o capitana de un barco por Punta Arenas o Azores. Pero poco hay de eso o de cierta Europa (1990) en el libro del mismo nombre de otro de los mejores poetas del momento: Julio Martínez Mesanza. Ni en Las trincheras, de 1996. Ciertamente los poemas de uno y otro libro podrían intercambiarse sin problemas en ese sentido literario y medieval de una Europa de otro tiempo, que literaturiza, bajo diferente título. Ciertamente su relación con el presente es pura entelequia, si no se quiere sobreinterpretar, salvo una lectura en que no quiero creer de sus textos desde su poética. Interpretar desde el título los libros de Mesanza, incluidos sus aspectos más conservadores sería un ejercicio hipócrita ante un poeta que mira con dolor lo mínimo, hombres o caballos muertos en combate, desde su mundo alegórico, literario y alejado de suprematismos, 
pese a su indudable conservadurismo simbólico y poco atento a los lados, a la implicación o a la vida real, que sortea desde la historia. Un poeta mucho más sugerente e importante de cuanto los últimos tiempos vienen tendiendo en el patio, pues su mundo histórico y alegórico es fuente propiciatoria en muchos sentidos literarios que se encaminan en uno abierto plural, como fue el de Cavafis desde el huerto griego o la Magna Grecia, según se mire.

En cualquier caso, vamos a estudiar desde el título/ausencia de título desde la luna, Selene, Cintia, en dos gaditanos. En los primeros libros de Rafael Alberti y en Felipe Benítez Reyes. Tal y como es fácil comprobar la diosa blanca de los mitos presocráticos estudiada por Robert Graves, la luna, aparece en Alberti profusamente en los poemas anteriores a Marinero en tierra, sin titular el poema directamente con su nombre, sino tomándola por alguna cuestión en general, como ocurrirá más adelante con una oración heterodoxa, divinizándola en lugar de la virgen María. La luna en los poemas previos se identifica con un escolar castigado en un rincón, con la plaza de toros, pero siempre sin título. Normalmente, luz salvífica y que da tranquilidad «25» (2003: 216), propicia encuentros de amantes o acompaña al viajero, puede volverse hostil en Sobre los ángeles en «Luna enemiga» (2003: 567), con el nombre y el asunto explícito, y rompiendo así los viejos moldes en la manera de abordar la luna que había escogido en el neopopularismo anterior. Con el hombre nuevo, comprometido, llegará también esta luna, enemiga del pasado y del hombre deshabitado, para reclamar en clave surrealista la llegada de los nuevos tiempos. Este sería un trazado sucinto de esa titulación y tratamiento de asunto, con o sin título, en dos brochazos obligados.

Con Benítez Reyes llega una luna melancólica y asida al dios Tiempo. Ya en uno de sus últimos libros La misma luna de 2007 , aparece con ese papel de ser la misma y fluyente, como el agua heraclitana, siempre la misma, pero siempre otra, luna o agua. Así, en el prólogo, se nos indica este sentido muy en consonancia con el libro, si bien puede ser hechicera, pura plasticidad entre nubes de éter, o submarina y caída como Ofelia en «Acuarela contradictoria» (2009: 347). La luna es la barroca de luces y sombras «Teatro de luz vívida y tiniebla»; es el gran teatro del mundo desde el claroscuro barroco con que la hiperestesia de Benítez Reyes asume una aguzada presencia del trascurrir del tiempo. No mentía el prólogo, ni el contexto que da esas pistas sobre los senderos unívocos y obsesivos del estupendo poeta gaditano, tanto como el olvidado José Mateos. Con esta perspectiva vamos asistiendo sin titulación explícita una serie de poemas lunares, salvo los citados y «La luna», que «define lo triste / en las literaturas y códigos de amor» (2009: 292). Luna y muerte, luna y tiempo se van reiterando obsesivamente en el gaditano como una constante narcótica, bajo el deseo, bajo su imán fascinante y mágico, hechicero, hasta el estupor de lo inefable. Un anclaje más en esa construcción que ratifica desde título, texto, contexto y trayectoria, la mirada elegíaca de Felipe Benítez Reyes. 


\section{Bibliografía}

Alberti, Rafael (2003), Obra Completa, Tomo I, Ed. Jaime Siles, Barcelona, Seix Barral.

Benítez Reyes, Felipe (2009), Libros de poemas, Madrid, Visor.

Burguera, Ma Luisa (2004), Textos clásicos de teoría de la literatura, Madrid, Cátedra.

Cabo Aseguinolaza, Fernando \& Gullón, Germán (1998), Teoría del poema, Amsterdam, Rodopi.

Eliot, T. S. (I992), Sobre poesía y poetas, Barcelona, Icaria.

García Berrio, Antonio (I994), Teoría de la literatura. (La construcción del significado poético), Madrid, Cátedra.

Genette, Gérard (200I), Umbrales, México, Siglo XXI.

Iravedra, Araceli (20Io), El compromiso después del compromiso. Poesía, democracia y globalización (poéticas I980-2005), Madrid, UNED.

Morales Barba, Rafael (2008), La musa funámbula, Madrid, Huerga y Fierro.

-. (20I7), Poéticas del malestar, Prólogo de Antonio Gamoneda, Rentería, Gallo de oro. 